Reprinted fron the "Proceedings of the Indian Academy of Sciences", Vol. LIX, 1964

\title{
STANDARDIZATION OF C14 STOCK SOLUTION AND FILTER EFFICIENCY IN THE COMPARISON OF PRIMARY PRODUCTIVITY MEASUREMENTS
}

BY

R. Raghu Prasad, P. V. Ramachandran Nair and J. J. A. Mclaughlin 


\title{
Roprinted from "The Proceedings of the Indian Academy of Sciencesi", \\ Vo!. LIX, No. S. Sec. B, 1964
}

\section{STANDARDIZATION OF C14 STOCK SOLUTION AND FILTER EFFICIENCY IN THE COMPARISON OF PRIMARY PRODUCTIVITY MEASUREMENTS}

\author{
By R. Raghu Prasad, F.A.Sc., * P. V. Ramachandran NaIR \\ AND J. J. A. MCLAUGHLIN** \\ (Central Marine Fisheries Research Institute, Mandapam Camp) \\ Received December 14, 1963
}

\section{INTRODUCTION}

DURING the intercalibration trials on primary production conducted at the University of Hawaii, Honolulu, in September 1961, in which one of the authors (R.R.P.) also participated, factors influencing the variability of productivity measurements like sampling error, differential toxicity of samplers, sample treatment before incubation, inoculation, incubation, planchet prepa ration and counting were considered. Of these some of the factors such as sampling error and inoculation were made uniform by each group of scientists sub-sampling one and the same sample and all participants using the same C' ${ }^{14}$ stock (C.S.I.R.O., Australia, No. 9). Different techniques were used only for incubation and two techniques were used for counting (for details see Doty, 1961).

The method for the measurement of primary production, followed in this Institute till recently, was on the lines marked out by the International Agency for $\mathrm{C}^{14}$ Determination at Charlottenlund, Denmark, including the computation of photosynthetic rates (see Steemann Nielsen, 1958). 'Since all the equipments used in this technique were not available at the time of the intercalibration tests at Hawaii, techniques used by participants from Australia, Japan, U.S.A. and U.S.S.R. only were compared. But later during July 1962 to June 1963 the first two authors conducted a series of parallel in situ experiments in inshore waters using the same C.S.I.R.O. stook of $\mathrm{C}^{14}(8 . \mu \mathrm{C})$, filters and filtering device as well as those of the International Agency $(4 \mu \mathrm{c})$. The counting of the planchets was done by the C.S.I.R.O. and the International Agency respectively.

\footnotetext{
** Present address: Central Marine Fisheries Research Substation, Ernakulam.

$\uparrow$ Haskins Laboratories, New York, U.S.A., under U.S.P.H. GM-OToe2, suppont in part and

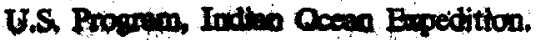


The first two authors are thankful to Dr. G. F. Humphrey and Dr. H. R. Jitts of C.S.I.R.O., Australia, for the stock of $\mathrm{C}^{14}$, filters and filtering apparatus and for also arranging the counting of the planchets.

\section{RESULTS}

Twenty-eight in situ experiments were conducted mostly in the inshore waters of Palk Bay using replicate samples containing natural population and under identical conditions. The results are given in Table I.

In the final values of primary production a $10 \%$ correction has been applied by the Agency for isotopic discrimination and respiration of $\mathrm{C}^{\mathbf{1 4}}$, whereas for values from C.S.I.R.O. counting this correction has not been applied. Though any similarity in the activities of the two sets of planchets is not to be expected because of the difference in the strength of the stocks as well as the efficiencies of the counting systems, there should have been greater agreement in the ultimate values especially in view of the high sensitivity of the technique. The almost consistently lower rates in the C.S.I.R.O. values cannot be due to the higher added activity since the strength of $\mathrm{C}^{\mathbf{1 4}}$ is of no importance. Nevertheless, experiments were conducted with dilutions of $1,2,4,5$ and $10 \mu \mathrm{c}$ from a Nuclear Chicago 0.5 millicurie stock solution of sodium carbonate and these gave proportional recovery of activity $(173,181,410,461$ and 920 c.p.m. respectively) in a gas flow proportional counter. It may be mentioned here that the respective figures of 'added activity' at zero-thickness used in the computation of photosynthetic rates have been obtained by two different techniques (exponential extrapolation in the Agency technique and calculated from absolute activity in the C.S.I.R.O. technique). According to Jitts and Scott (1961) the value obtained by exponential extrapolation can be low by $26 \%$ (subsequently corrected to $20 \%$ by Jitts, 1961) as compared to the latter method. The application of a lower value of added activity brings an overestimation in the production values. Hence it is obvious that the difference in approach in the standardization of stock is partly responsible for the observed disparity in the production values obtained by the two techniques.

Various methods have been used for the measurement of added activity, such as drying small aliquot of the stock solution on a planchet or converting to gaseous $\mathrm{C}^{14} \mathrm{O}_{2}$ and determining in a gas counter and the more common method of determining indirectly from self-absorption curves of $\mathrm{BaCO}_{3}$ planchets of varying thickness (ref. Jitts, 1961). While discussing the merits and demerits of these methods Jitts (op. cit.) has remarked that though the extrapolation of self-absorption curves can be made to be highly reproducible 
Standardization of $C^{14}$ Stock Solution and Filter Efficiency

TABLE I

Comparison of values of in situ experiments in Palk Bay obtained by the International Agency and C.S.I.R.O. techniques

\begin{tabular}{|c|c|c|c|c|c|c|c|}
\hline \multirow{2}{*}{$\begin{array}{l}\text { Expt. } \\
\text { No. }\end{array}$} & \multirow[b]{2}{*}{ Date } & \multirow[b]{2}{*}{ Station } & & \multicolumn{2}{|c|}{ International Agency } & \multicolumn{2}{|c|}{ C.S.I.R.O. Australia } \\
\hline & & & & c.p.m.* & $\underset{\text { hour }}{\operatorname{mg.~}} \mathrm{C} / \mathrm{m} \cdot{ }^{3} /$ & c.p.m. $\dagger$ & $\underset{\text { hour }}{\operatorname{mg.~} \mathrm{C} / \mathrm{m} \cdot{ }^{3} /}$ \\
\hline 1 & $26-6-1962$ & Off Mandapam & $\mathbf{S}$ & 10,921 & $60 \cdot 175$ & 36,360 & $22 \cdot 875$ \\
\hline 2 & " & , & B & 1,576 & $8 \cdot 684$ & 7,412 & $4 \cdot 663$ \\
\hline 3 & 4-7-1962 & , & $\mathbf{S}$ & 32,122 & $132 \cdot 760$ & 24,915 & $11 \cdot 756$ \\
\hline 4 & , & , & $\mathbf{M}$ & 7,476 & $30 \cdot 898$ & 43,568 & $20 \cdot 557$ \\
\hline 5 & , & , & B & 720 & $2 \cdot 975$ & 3,663 & $1 \cdot 728$ \\
\hline 6 & $9-7-1962$ & $"$ & S & 18,863 & $77 \cdot 961$ & 76,564 & $36 \cdot 126$ \\
\hline 7 & , & ", & $\mathbf{M}$ & 731 & $3 \cdot 021$ & 2,881 & $1 \cdot 359$ \\
\hline 8 & $"$ & , & B & 514 & $2 \cdot 124$ & 2,102 & 0.992 \\
\hline 9 & $11-7-1962$ & Off Thangachimadam & $\mathbf{S}$ & 10,620 & $43 \cdot 892$ & 27,897 & $13 \cdot 163$ \\
\hline 10 & , & , & $\mathbf{M}$ & 2,019 & $8 \cdot 344$ & 10,294 & $4 \cdot 857$ \\
\hline 11 & ", & , & B & $122 \cdot 6$ & 0.507 & 907 & 0.428 \\
\hline 12 & $"$ & " & $S(D)$ & 93.6 & 0.258 & 783 & 0.246 \\
\hline 13 &, & , & B (D) & $71 \cdot 6$ & $0 \cdot 197$ & 726 & 0.228 \\
\hline 14 & $18-7-1962$ & Off Athangarai & $\mathbf{S}$ & 5,553 & $30 \cdot 791$ & 27,832 & $15 \cdot 759$ \\
\hline 15 & " & , & $\mathbf{M}$ & 2,565 & $14 \cdot 223$ & 13,809 & $7 \cdot 819$ \\
\hline 16 &. & ", & B & 396 & $2 \cdot 196$ & 1,432 & 0.811 \\
\hline 17 & " & $"$ & $S(D)$ & $122: 6$ & 0.338 & 434 & $0 \cdot 137$ \\
\hline 18 & , & ", & $\mathrm{B}(\mathrm{D})$ & $37 \cdot 1$ & $0 \cdot 102$ & 470 & $0 \cdot 148$ \\
\hline 19 & 4-9-1962 Off & f Vizhingam & $\mathbf{S}$ & 1,984 & $7 \cdot 55$ & 12,652 & $5 \cdot 97$ \\
\hline 20 & " & $"$ & $15 \mathrm{~m}$. & 299 & $1 \cdot 14$ & 1,358 & 0.64 \\
\hline 21 & " & ", & $30 \mathrm{~m}$ & $67 \cdot 5$ & 0.26 & 296 & $0 \cdot 13$ \\
\hline 22 & $11-6-1963$ off & Mandapam & $\mathbf{S}$ & 1,291 & $7 \cdot 31$ & 10,692 & $5 \cdot 05$ \\
\hline 23 & , & , & $\mathbf{M}$ & 1,043 & $5 \cdot 90$ & 10,018 & $4 \cdot 73$ \\
\hline 24 & $"$ & $"$ & B & $50 \cdot 2$ & $0 \cdot 28$ & 483 & 0.23 \\
\hline 25 & $17-6-1963$ & , & $\mathbf{S}$ & 2,067 & $11 \cdot 70$ & 16,493 & $7 \cdot 78$ \\
\hline 26 & " & $"$ & $4 \mathrm{~m}$. & 3,235 & $18 \cdot 31$ & 23,738 & $11 \cdot 20$ \\
\hline 27 & " & ", & $8 \mathrm{~m}$. & 1,498 & $8 \cdot 48$ & $.15,002$ & 7.08 \\
\hline 28 & , & $"$ & $10 \mathrm{~m}$ & 626 & $3 \cdot 54$ & 6,863 & $3 \cdot 24$ \\
\hline
\end{tabular}

Added activity at zero-thickness $1.033 \times 10^{8}$ c.p.m.

$\dagger$ Added activity at zero-thickness $8.67 \times 10^{8}$ c.p.m.

S, Surface; B, Bottom; M, Middlelayer; D, Dark bottle, 


\section{- TABLE II}

Comparative retention of activity on 3 types of filters of varying pore sizes

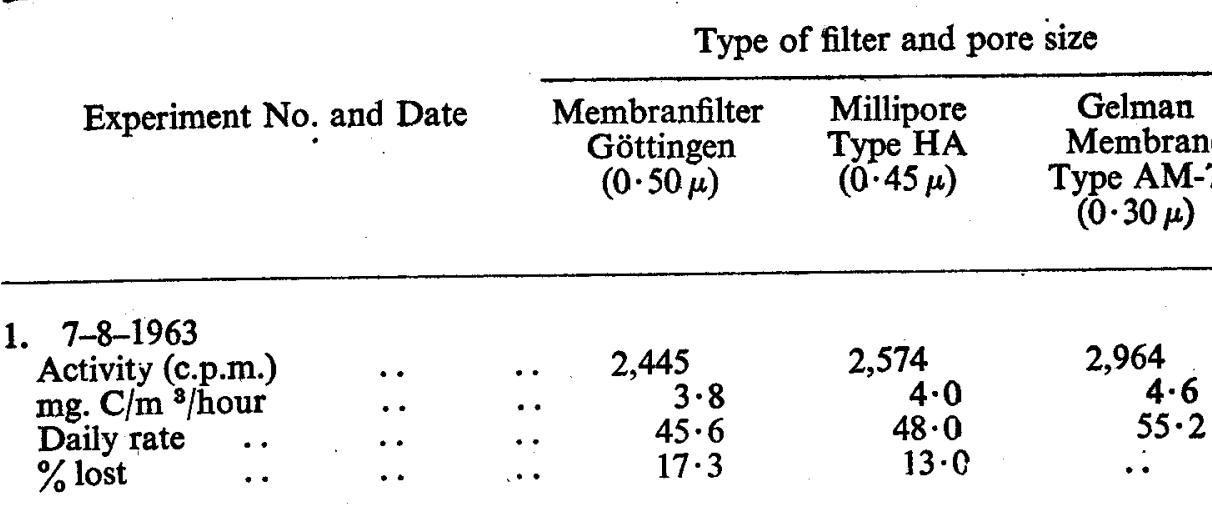

2. 8-8-1963

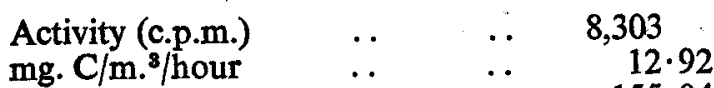

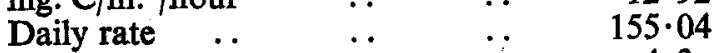

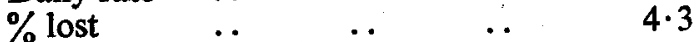

Recovered activity (c.p.m.) $\quad \ldots$

3. $12-8-1963$

$\begin{array}{lllr}\text { Activity (c.p.m.) } & \ldots & \ldots & 7,408 \\ \text { mg. C/m. } 3 \text { /hour } & \ldots & \ldots & 11 \cdot 53\end{array}$

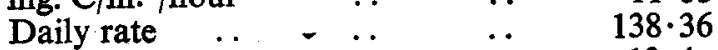

$\begin{array}{lllll}\% \text { lost } & . . & \ldots & \ldots & 13 \cdot 4\end{array}$

Recovered activity (c.p.m.) $\quad$.. 100

8,434
$13 \cdot 13$
$157 \cdot 56$
$2 \cdot 8$
238

$(8,672)$

$(13 \cdot 50)$

$(162 \cdot 00)$

..

$\cdots$

4. $17-8-1963$

Activity (c.p.m.)

mg. $\mathrm{C} / \mathrm{m} \cdot{ }^{3} /$ hour

Daily rate .

$\%$ lost

Recovered activity (c.p.m.)

\begin{tabular}{llc}
$\ldots$ & $\ldots$ & 51,649 \\
$\therefore$ & $\cdots$ & $83 \cdot 74$ \\
$\cdots$ & $\ldots$ & $1,004 \cdot 88$ \\
\hdashline & $\ldots$ & $9 \cdot 2$ \\
p.m.) & $\cdots$ & $\cdots$
\end{tabular}

8,087

8,553

$151 \cdot 08$

$5 \cdot 4$

67

$159 \cdot 72$

.

..

5. $17-8-1963$

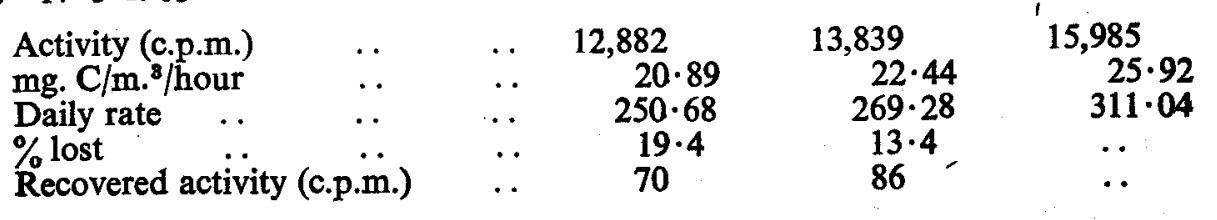

The figures in brackets in experiment 2 were obtained by filtering the filtrate from Millipore on Gelman filter after the original filtration on the latter went wrong. 
and can be used for relative measurements of primary production it can introduce considerable errors when measurements using different counters are compared. The above series of experiments clearly illustrate this fact and stress the need for the adoption of a uniform method of standardization of the stock to make the results of various workers comparable. It is felt that the method suggested recently by Jitts and Scott (1961) which consists of determining the absolute activity of the $\mathrm{C}^{14}$ added and the efficiency of the counter at zero-thickness and thereby the added activity could offset much of the difficulty and make comparison of values more feasible.

Another important aspect in productivity measurements, which has not received much attention, is the comparative efficiency of the filters commonly used by different workers in the retention of the activity. Lasker and Holmes (1957) studied the variability in retention of marine phytoplankton labelled with $\mathrm{C}^{14}$ and concluded that it is advisable to employ filters with a porosity of at least $0.45 \mu$ and with relatively rapid flow characteristics. Recently Thomas (1961) has rightly drawn attention to the need of obtaining more knowledge of just how fine a filter is necessary to retain all or most of the radioactivity from $\mathrm{C}^{14}$ labelled populations and also what negative pressure should be used for filtrations. During the intercalibration trials Millipore filters AA grade (pore size $0.8 \mu$ ) were used throughout. In the experiments mentiond above the authors used Millipore AA filters for the C.S.I.R.O. stock and Göttingen Membranfilter $(0 \cdot 5 \mu)$ for the Agency stock. AA filters retain less activity than HA filters $(0.45 \mu)$ and considering the significance of the contribution of nanno-plankton in the primary production of these waters HA filters have been used for routine work in this Institute. Steemann Nielsen also has pointed out in a recent personal communication that for plankton algae like naked flagellates the filtration efficiency is an important factor.

In order to assess the relative efficiency of filters few experiments were conducted in August 1963 when the third author was here under the U.S. Program of Biology in connection with the International Indian Ocean Expedition. Natural populations were usedland the retention of activity was measured on Millipore HA filters, Göttingen Membranfilter supplied along with the Intetinational Agency stock and also Gelman Membrane filters Type AM-7 having a smaller pore size $(0 \cdot 30 \mu)$.

Table II gives the results of these experiments.

It may be seen that excepting in experiment 4 when phytoplankton was very abundant in the sample, Golman filters showed a higher rotention of 
activity than the other filters. The decrease in retention on Gelman filter in experiment 4 may, in all probability, be due to rupturing of the cells during filtration as stated by Thomas (op. cit.) after the initial deposition of cells and further reduction of porosity of the filter, as phytoplankton was abundant in this sample. The higher values obtained by HA filters over Göttingen filters are also not altogether insignificant. This may be either due to the slight difference in pore size or due to the difference in the filtration techniques (vacuum for HA and pressure for the latter). The higher retention of activity of the Gelman filters was also indicated, when the filtrate from Millipore HA and Göttingen filters were refiltered at random through Gelman filters (see Table II, recovered activity). Hence it is felt that for plankton-rich waters, filters of Millipore HA type $(0.45 \mu)$ and for plankton-sparse waters, filters with smaller pore size like Gelman Membrane type AM-7 (pore size $0.30 \mu$ ) and less would be suitable yielding more comparable results.

The results of these observations reveal that the adoption of a uniform method of standardization of stock solution and careful selection of the type of filters are necessary more than anything else if values obtained by different workers are to be compared with reasonable accuracy in view of the high sensitivity and wide popularity which the Carbon-14 technique commands.

\section{SUMmaRY}

Parallel experiments using natural populations were conducted to find out the variability of values of organic production obtained by two different $\mathrm{C}^{14}$ stock solutions, standardization techniques and counting systems as well as the relative efficiency of three types of filters. The results indicate that a uniform method of standardization of stock solution and a careful selection of filters are necessary more than anything else if values of organic production obtained by different workers are to be compared.

\section{REFERENCES}

Doty, M. S.

Jitts; H. R.

and Scott, B. D.

\section{.. "Analysis of the productivity data from the September, Honolulu, intercalibration trials," Mimeo, 1961.}

.. "The standardization and comparison of measurements of primary production by the Carbon-14 technique," Proceedings of the Conference on Primary Productivity Measurement, Marine and Freshwater, held at University of Hawall, August 21 to September 6, 1961, Ed. M.S. Doty, 1961, TID-7633, 114-20.

- "The determination of zero-thickness activity in Geiger counting of C-14 solutions used in marine productivity studies," Limnol, Oceanogr., 1961, 6 (2), 116-23, 


\section{Standardization of $C^{11}$ Stock Solution and Filter Efficiency 251}

Lasker, R. and Holmes, R. W. "Variability in retention of marine phytoplankton by membrane filters," Nature, 1957, 180, 1295-96.

Stcomann Nielsen, E.

"Experimental methods for measuring organic production in the sea," Rapp. Proc.-Verb. Cons. Int. Explor. Mer., $1958,144,38-46$.

Thomas, W. H.

.. "Physiological factors affecting the interpretation of phytoplankton production measurements," Proceedings of the Conference on Primary Productivity Measurement, Marine and Freshwater, held at University of Hawail, August 21 to September 6, 1961, Ed. M.S. Doty, 1961, TID-7633, 147-62. 